\title{
The presence of conifer resin decreases the use of the immune system in wood ants
}

\author{
GRÉGOIRE CASTELLA ${ }^{1}$, MICHEL CHAPUISAT ${ }^{1}$, YANNICK MORET ${ }^{2}$ \\ and P H I L I P P E C H R I S T E ${ }^{1}{ }_{1}^{1}$ Department of Ecology and Evolution, Biophore, University of \\ Lausanne, Lausanne, Switzerland and 'Équipe Écologie Évolutive, UMR CNRS 5561 BioGéoSciences, \\ Université de Bourgogne, Dijon, France
}

\begin{abstract}
Wood ants (Formica paralugubris) incorporate large amounts of solidified conifer resin into their nest, which reduces the density of many bacteria and fungi and protects the ants against some detrimental micro-organisms. By inducing an environment unfavourable to pathogens, the presence of resin may allow workers to reduce the use of their immune system.

2. The present study tested the hypothesis that the presence of resin decreases the immune activity of wood ants. Specifically, three components of the humoral immune defences of workers kept in resin-rich and resin-free experimental nests (antibacterial, lytic, and prophenoloxidase activities) were compared.

3. The presence of resin was associated with reduced bacterial and fungal densities in nest material and with a small decrease in worker antibacterial and lytic activities. The prophenoloxidase activity was very low in all workers and was not affected by the presence of resin.

4. These results suggest that collective medication with resin reduces pathogen pressure, which in turn decreases the use of the inducible part of the immune system. More generally, the use of plant secondary compounds might be an efficient and economical way to fight pathogens.
\end{abstract}

Key words. Antibacterial activity, Formica paralugubris, immunity, lytic activity, medication, plant secondary metabolites, prophenoloxidase.

\section{Introduction}

Parasites are widespread and almost all organisms face their attack. As parasites reduce the fitness of their host, hosts have evolved behavioural and immune defence mechanisms to counteract these negative effects. When resource limited, hosts often have to divert some resources from other fitness-related traits in order to re-allocate them to defence mechanisms (Williams, 1966; Coustau et al., 2000).

To better resist parasites, hosts have evolved behavioural strategies (Hart, 1990), such as parasite avoidance (Christe et al., 1994), grooming (Mooring et al., 2004), hygienic behaviours (Arathi et al., 2006), and self-medication (Lozano, 1998; Christe et al., 2003; Chapuisat et al., 2007). These behaviours are likely to be associated with two types of costs. First, the

Correspondence: Grégoire Castella, Department of Ecology and Evolution, Biophore, University of Lausanne, CH-1015 Lausanne, Switzerland. E-mail: gregoire.castella@unil.ch behaviour may be energetically costly (Giorgi et al., 2001) and, second, the time spent performing the behaviour may be lost for other tasks such as feeding, resting, or reproducing (Christe et al., 1996; Eckstein \& Hart, 2000; Hawlena et al., 2007).

The second line of defence is the immune system. Immunity, which relies on both cellular and humoral mechanisms to recognise and respond to non-self entities, is mainly innate in insects (Gillespie et al., 1997). A common factor that links all components of immune function is that they are supposed to be costly (Sheldon \& Verhulst, 1996; Schmid-Hempel, 2005). Physiological costs are indeed likely to be associated with both the maintenance and the activation of the immune system (Rolff \& Siva-Jothy, 2003). Whereas the costs of maintenance are intrinsically difficult to quantify (Lochmiller \& Deerenberg, 2000; Schmid-Hempel, 2003), activation costs are readily measured and have been demonstrated (reviewed in Siva-Jothy et al., 2005). In bumblebees, for instance, immune system activation reduces the workers' survival under starvation (Moret \& SchmidHempel, 2000) and the reproductive success of the colony (Moret \& Schmid-Hempel, 2004).

(C) 2008 The Authors Journal compilation @ 2008 The Royal Entomological Society 
Anti-parasite behaviours and immunity may be used alternatively and investment in one type of defence may permit reduced investment in another type. More specifically, as the expression of immune defences is phenotypically plastic and is thus likely to be modulated according to environmental factors (Siva-Jothy et al., 2005), a behaviour that decreases exposure to parasites should result in lower use of the immune system, either by permitting a reduced investment in constitutive defences or by lessening activation of inducible responses.

The medication behaviour of wood ants (Formica paralugubris) provides an interesting model to test for such a trade-off between behavioural defences and immunity. Workers of this species actively collect pieces of solidified conifer resin from their habitat and incorporate them into their mounds (Castella et al., 2008). Resin, produced by conifer trees when attacked by insects or mechanically wounded (Martin et al., 2002), contains a complex mixture of mono- and sesqui-terpenes showing antibacterial and antifungal properties (Cowan, 1999; Phillips \& Croteau, 1999). Recent studies have demonstrated that this medication behaviour provides benefits in terms of defence against pathogens. The resin reduces the densities of bacteria and fungi in ant nest material and inhibits in vitro the growth of some potential ant pathogens (Christe et al., 2003). It also increases the survival of experimentally infected ants (Chapuisat et al., 2007). Resin, by inducing an unfavourable environment to pathogens in the nest, reduces the probability and the potential costs of parasitic infections. To collect resin may thus allow workers to invest fewer resources in immunity.

The aim of this study is to test whether the conifer resin present in wood ant nests permits a reduction in worker's immune activity. Resin-rich and resin-free experimental nests were created and the immune activity of workers kept in these two types of nests was compared. More precisely, three components of their humoral activity were tested, namely the antibacterial, lytic, and prophenoloxidase activities. As resin decreases the densities of fungi and bacteria in wood ant nest material, lower activity in all three immune components is predicted.

\section{Methods}

\section{Sampling}

In October 2004, 20 litres of nest material and workers were collected from 10 randomly chosen nests of the study population located near the Chalet à Roch in the Swiss Jura Mountains. Nest material was sampled from within the upper part of the mounds, and consisted of twigs and spruce needles. Nest material and workers from all colonies were mixed together, taking advantage of the lack of aggression between individuals of this population (Holzer et al., 2006). All pieces of resin were removed with soft forceps and kept apart.

\section{Experimental nests}

In order to create 30 experimental nests, the homogeneous stock of workers and nest material was split into 30 parts. Each part, consisting of approximately 0.6 litres of nest material and 200 workers, was deposited in a plastic container $(21 \times 37 \times 18 \mathrm{~cm})$ side-coated with Fluon to prevent ants from escaping. One tube filled with liquid food (distilled water with $8 \%$ honey) and one tube filled with distilled water were deposited in each container. Half of the nests were allocated to the resin-rich group and the other half to the resin-free group. In each of the nests of the former group, $6 \mathrm{~g}$ of resin (corresponding to $\sim 300$ pieces) were deposited on the surface of the nest material. All experimental nests were kept for 35 days at $25^{\circ} \mathrm{C}$ with a LD $12: 12 \mathrm{~h}$ cycle and with regular vaporisation of sterile water to maintain high humidity.

In order to verify that the presence of resin effectively reduced bacterial and fungal densities in the experiment, the concentration of micro-organisms in the nest material of each experimental nest after 35 days was assessed, as described in Christe et al. (2003). A significantly lower number of bacterial colony-forming units (CFU) was measured in the resin-rich experimental nests as compared to the resin-free ones (mean $\pm \mathrm{SD}$ of $\mathrm{CFU}$ per $10^{-9} \mathrm{~g}: 2.81 \pm 0.19$ and $3.67 \pm 0.19$ in nests with resin and without resin respectively; $t_{28}=3.05, P=0.005$ ). The density of fungi was also significantly lower in resin-rich nests as compared to resin-free ones (square-root transformed mean \pm SD of CFU per $10^{-4} \mathrm{~g}: 1.11 \pm 0.31$ and $1.40 \pm 0.27$ in nests with resin and without resin respectively; $t_{27.6}=2.69, P=0.01$ ). The mean number of CFU formed by gram-negative bacteria in the resinrich nests was however not significantly different from the one found in resin-free nests (Mean \pm SD of CFU per $10^{-9} \mathrm{~g}$ : $3.48 \pm 0.29$ and $3.58 \pm 0.29$ in nests with resin and without resin respectively; $t_{28}=0.24, P=0.81$ ). These results confirm that the resin treatment significantly reduced the microbial load in nest material (Christe et al., 2003).

For all workers tested for immune activity, body size was estimated from the measure of head size with a stereomicroscope Nikon Profile V-12 (Schwander et al., 2005). There was no difference in the mean head size between resin-rich and resin-free nests, both after 15 and 35 days (mean head size per nest $\pm \mathrm{SE}$ in millimetres; day 15: $1.48 \pm 0.02$ for the resin-rich group and $1.51 \pm 0.02$ for the resin-free group, $t_{27.1}=1.32, P=0.20$; day 35: $1.47 \pm 0.02$ for the resin-rich group and $1.48 \pm 0.01$ for resin-free group, $t_{25.3}=0.69, P=0.50$ ).

\section{Immune measures}

The immune defences were measured for five and ten workers per experimental nest sampled 15 and 35 days after the start of the experiment respectively. Immune defences were measured individually on worker homogenates. Workers were put in $0.5 \mathrm{ml}$ Eppendorf tubes and chilled on ice. The three last segments of the abdomen and the head were removed. The thorax and the remaining part of the abdomen were put in a tube containing $30 \mu \mathrm{l}$ of sodium cacodylate $\left(\mathrm{Na}-\mathrm{Cac}\right.$ : $0.01 \mathrm{~m} ; \mathrm{CaCl}_{2}$ : $0.005 \mathrm{~m}$ ) and squashed with a pellet pestle. The sample was then vortexed for $1 \mathrm{~min}$ and centrifuged $(6600 \mathrm{rpm})$ for $15 \mathrm{~min}$ at $4{ }^{\circ} \mathrm{C}$. Twenty microlitres of the supernatant were collected and immediately frozen at $-80^{\circ} \mathrm{C}$.

The antibacterial and lytic activities were measured with the inhibition zone (Moret \& Schmid-Hempel, 2000) and clearing 
zone (Y. Moret, pers. comm.) assays respectively. These two assays consist of depositing a drop of homogenate solution on a culture medium inseminated with live bacteria for the inhibition zone and with bacterial cell walls extract for the clearing zone assays. The antibacterial and lytic activities of the sample are proportional to the surface of the zone where bacterial growth has been inhibited and to the surface of the zone where cell walls have been lysed respectively.

For the inhibition zone assay, $2 \mu$ l of the homogenate solution were placed on the surface of a thin layer of agar $(6 \mathrm{ml}$ in Petri dishes, diameter $9 \mathrm{~cm}$; agar recipe: $10 \mathrm{~g}$ bactotryptone, $10 \mathrm{~g}$ bacto-agar, $10 \mathrm{~g} \mathrm{NaCl}, 5 \mathrm{~g}$ yeast extract, $1000 \mathrm{ml}$ distilled water, $\mathrm{pH}$ 7.5) mixed with the test bacteria Arthrobacter globiformis (Institut Pasteur Paris, nr. $81.84 \mathrm{~T}$ ) adjusted to $10^{5}$ cells $\mathrm{ml}^{-1}$. After overnight incubation at $30^{\circ} \mathrm{C}$, the minimum and maximum diameters (in $\mathrm{mm}$ ) of each zone of inhibition were measured and their mean was used to calculate the surface of the corresponding area [with the formula: $\pi$ (mean diameter $/ 2)^{2}$ ].

For the clearing zone assay, $2 \mu 1$ of the homogenate solution were placed on the surface of a thin layer of agar $(5 \mathrm{ml}$ in lids of cell culture plates; agar recipe: $1 \mathrm{~g}$ bacto-agar, $10 \mathrm{mg}$ streptomycin sulphate, Triton X-100 2\%, $100 \mathrm{ml}$ distilled water) mixed with Micrococcus luteus cell walls extract (Sigma, $5 \mathrm{mg} \mathrm{ml}^{-1}$ ). After overnight incubation at $30{ }^{\circ} \mathrm{C}$, the minimum and maximum diameters (in $\mathrm{mm}$ ) of each zone of lysis were measured and their mean was used to calculate the surface of the corresponding area.

Prophenoloxidase activity was measured as described by Moret and Siva-Jothy (2003), with slight modifications. The total amount of enzymes is proportional to the increase in optical density induced by the transformation of L-DOPA to dopachrome by phenoloxidase (Soderhall \& Cerenius, 1998). Samples were tested in a 96-well microplate reader. Ten microlitres of homogenate solution were mixed with $10 \mu$ l of phosphate-buffered saline (PBS) and $50 \mu \mathrm{l}$ of trypsin $(0.25 \%)$ in a microplate well and left for $5 \mathrm{~min}$ at room temperature. Trypsin proteolytically activates prophenoloxidase (the inactive form of the enzyme) into phenoloxidase (the active form) and thus allows measurement of the total enzymatic activity of the sample. Ten microlitres of L-DOPA $\left(4 \mathrm{mg} \mathrm{ml}^{-1}\right)$ were then added to the mix. The mixture absorbance at $492 \mathrm{~nm}$ was measured at $30^{\circ} \mathrm{C}$ every $10 \mathrm{~s}$ for $50 \mathrm{~min}$. The prophenoloxidase activity was measured as the slope of the reaction curve during the linear phase of the reaction $\left(V_{\max }\right.$, i.e. the rate of change in optical density $\times 10^{2}$ per $\mathrm{s}$ ).

To evaluate the immune activity of workers before the start of the experiment, five workers were sampled per nest immediately after the split of the common stock of workers and they were tested for all three immune measures. As expected, no difference was found between the new experimental nests destined to be allocated to the two treatment groups (mean inhibition surface $\pm \mathrm{SE}$ in $\mathrm{mm}^{2}: 15.97 \pm 3.21$ in nests destined to be resinrich and $18.33 \pm 2.69$ in nests destined to be resin-free; $t_{27.2}=0.56, P=0.58$; log transformed mean lysis surface $\pm \mathrm{SE}$ in $\mathrm{mm}^{2}: 2.05 \pm 0.11$ in nests destined to be resin-rich and $2.05 \pm 0.13$ in nests destined to be resin-free; $t_{27.4}=0.01$, $P=0.99$; median prophenoloxidase activity: 0.064 in nests destined to be resin-rich and 0.108 in nests destined to be resinfree; Wilcoxon rank sum test, $Z=0.604, n=30, P=0.55$ ).

\section{Statistical analyses}

For all three immune measures, a nest mean was calculated for each sampling (i.e. on five workers per nest after 15 days and on 10 workers per nest after 35 days) and used as data point. Groups were compared using Student's $t$-tests (allowing unequal variance) when the data followed a normal distribution and Wilcoxon rank sum tests otherwise. To test for an overall effect of the treatment, a Z-transform test was used (Whitlock, 2005). Statistical analyses were carried out using JMP 6.0 (SAS Institute Inc., Cary, North Carolina).

\section{Results}

The antibacterial activity of workers from resin-rich and resinfree nests did not differ significantly after 15 days (one-tailed $t$-test: $t_{27.4}=0.24, P=0.403$; Fig. 1). However, after 35 days, workers kept in resin-rich nests had a significantly lower level of antibacterial activity than workers kept in resin-free nests (onetailed $t$-test: $t_{207}=2.02, P=0.028$; Fig. 1 ). Workers kept in resin-rich nests had a lower lytic activity than workers kept in resin-free nests after 15 days but this difference was no longer significant after 35days (one-tailed $t$-tests: after 15days, $t_{24.8}=1.80, P=0.042$; after 35 days, $t_{21.5}=1.31, P=0.102$; Fig. 2). Workers kept in resin-rich and resin-free nests did not differ significantly in their prophenoloxidase activity (Wilcoxon rank sum tests: after 15 days, $Z=-0.069, n=30, P=0.464$; after 35 days, $Z=0.251, n=30, P=0.408$; Fig. 3 ). When combining $P$-values of the comparisons on days 15 and 35 for the three immune components, the presence of resin was associated with a lower immune activity in workers ( $Z$-transform test, $P=0.013$ ).

\section{Discussion}

When pieces of solidified conifer resin are mixed into their nest material, wood ant workers show a small but significant decrease in their antibacterial and lytic activities. In contrast, prophenoloxidase activity does not seem affected by the presence of resin.

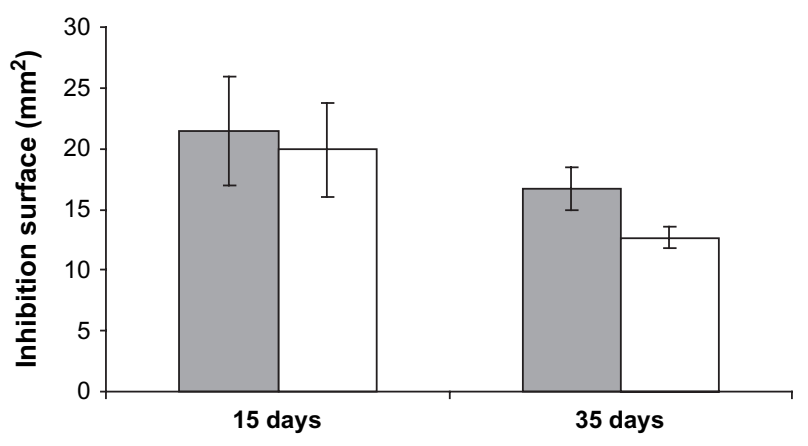

Fig. 1. Mean antibacterial activity expressed as inhibition zone surface $\pm \mathrm{SE}$ in $\mathrm{mm}^{2}$ for workers kept in resin-free (grey bars) and in resin-rich (white bars) nests, 15 days and 35 days after the beginning of the experiment. Nest means are used as data points. 


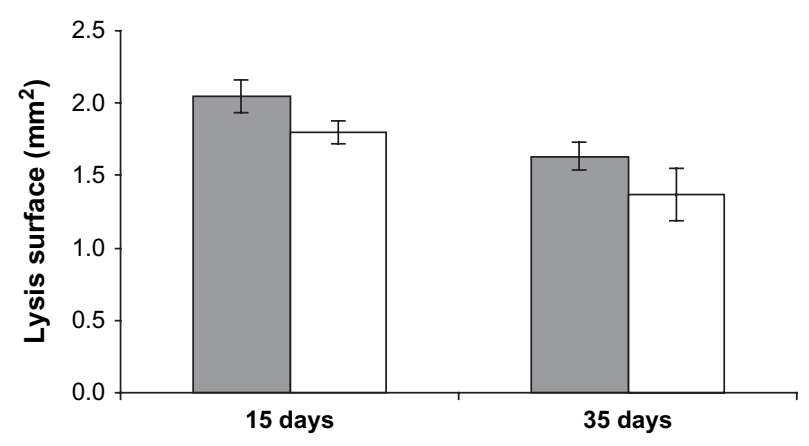

Fig. 2. Mean lytic activity expressed as lysis zone surface $\pm \mathrm{SE}$ in $\mathrm{mm}^{2}$ ( $\log _{\mathrm{e}}$ transformed) for workers kept in resin-free (grey bars) and in resin-rich (white bars) nests, 15 days and 35 days after the beginning of the experiment. Nest means are used as data points.

Antibacterial peptides and lysozyme, which are responsible for antibacterial and lytic activities respectively, are mainly produced by the insect fat body in response to bacterial or fungal infection (Gillespie et al., 1997). These two immune pathways are likely to be activated if the nest material contains high microbial densities. Resin inhibits the growth of bacteria and fungi (Christe et al. 2003; this study) and may thus reduce the activation of these inducible immune defences.

On the other hand, prophenoloxidase activity, considered a constitutive defence (Schmid-Hempel, 2005), was not impacted by the presence of resin in the nest. Prophenoloxidase is a zymogen that, once activated into phenoloxidase by proteolysis, leads to melanisation (Gillespie et al., 1997). Both in the pres-

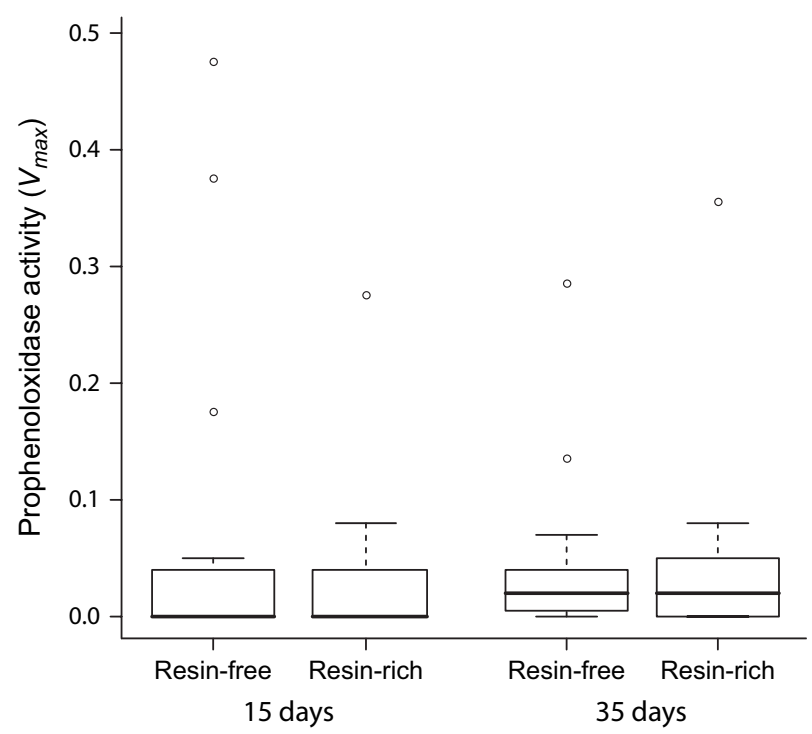

Fig. 3. Prophenoloxidase activity expressed as $V_{\max }$ for workers kept in resin-free and in resin-rich nests, 15 days and 35 days after the beginning of the experiment. Nest means are used as data points. Boxes correspond to the interquartile range and solid lines to the median for each group. Whiskers contain all points that are not further from the box than 1.5 times the interquartile range. ence and absence of resin, wood ant workers exhibit very low prophenoloxidase activity. Indeed only $13 \%$ of all the workers had detectable prophenoloxidase activity, whereas $69 \%$ and $58 \%$ of them showed antibacterial and lytic activities respectively. These proportions were not affected by the resin treatment. Wood ant workers therefore seem to invest little in the phenoloxidase cascade regardless of the presence of resin.

These results show that resin collection, by inducing unfavourable conditions for pathogens, results in a slightly lower activation of workers' inducible immune defences. In addition, the presence of resin reduced microbial densities in nest material (Christe et al., 2003) and increased the survival of infected ants (Chapuisat et al., 2007). As immune activation is likely to be associated with energetic costs, the resources spared might then be re-allocated to other fitness-related tasks (Siva-Jothy et al., 2005). Several studies in mammals and birds demonstrated that individuals in germ-free environments increased their productivity and growth (reviewed in Lochmiller \& Deerenberg, 2000).

Interestingly, plants may also reduce their level of defences in a reverse situation where plants use ants for their own protection. In myrmecophyte associations, plants provide food and shelter to ants that protect them against herbivorous insects (Heil \& McKey, 2003). It has been suggested that plants with active ant colonies have a lower level of chemical defences than plants that are not defended by ants (Dyer et al., 2001).

Many plant species produce secondary metabolites that are biologically active. Animals can recycle these complex substances and use them to fight pathogens (Hart, 2005) or defend themselves against predators (Eisner et al., 1974; Narberhaus et al., 2005). Sociality offers a new level of interactions and permits the collective use of the plant resources, along with many other social mechanisms that have evolved to counter the threat of parasites (Cremer et al., 2007). These various forms of social immunity may reduce the physiological costs of immune activation, and might in the long term even lead to simpler genetic immune systems, as indicated by the recent finding that honeybees lack several of the immune genes of non-social insects (Evans et al., 2006).

\section{Acknowledgements}

We thank Caroline Jeanneret and Aurélie Klopfstein for their important contribution to this study during their undergraduate training, Karen Osmont and two anonymous referees for useful comments on the manuscript and the Centre de Conservation de la Faune of the Canton de Vaud for permission to collect ants. This research was supported by grants 3100A0-104118 and 3100AO-108263 from the Swiss National Science Foundation.

\section{References}

Arathi, H.S., Ho, G. \& Spivak, M. (2006) Inefficient task partitioning among nonhygienic honeybees, Apis mellifera L., and implications for disease transmission. Animal Behaviour, 72, 431-438.

Castella, G., Chapuisat, M. \& Christe, P. (2008) Prophylaxis with resin in wood ants. Animal Behaviour, in press, doi:10.1016/ j.anbehav.2007.10.014. 
Chapuisat, M., Oppliger, A., Magliano, P. \& Christe, P. (2007) Wood ants use resin to protect themselves against pathogens. Proceedings of the Royal Society B, Biological Sciences, 274, 2013-2017.

Christe, P., Oppliger, A., Bancalà, F., Castella, G. \& Chapuisat, M. (2003) Evidence for collective medication in ants. Ecology Letters, 6 , 19-22.

Christe, P., Oppliger, A. \& Richner, H. (1994) Ectoparasite affects choice and use of roost sites in the great tit, Parus major. Animal Behaviour, 47, 895-898.

Christe, P., Richner, H., \& Oppliger, A. (1996) Of great tits and fleas: sleep baby sleep. Animal Behaviour, 52, 1087-1092.

Coustau, C., Chevillon, C. \& Ffrench-Constant, R. (2000) Resistance to xenobiotics and parasites: can we count the cost? Trends in Ecology \& Evolution, 15, 378-383.

Cowan, M.M. (1999) Plant products as antimicrobial agents. Clinical Microbiology Reviews, 12, 564-582.

Cremer, S., Armitage, S.A.O. \& Schmid-Hempel, P. (2007) Social immunity. Current Biology, 17, R693-R702.

Dyer, L.A., Dodson, C.D., Beihoffer, J. \& Letourneau, D.K. (2001) Trade-offs in antiherbivore defenses in Piper cenocladum: ant mutualists versus plant secondary metabolites. Journal of Chemical Ecology, 27, 581-592.

Eckstein, R.A. \& Hart, B.L. (2000) The organization and control of grooming in cats. Applied Animal Behaviour Science, 68, 131-140.

Eisner, T., Johnesse, J., Carrel, J., Hendry, L.B. \& Meinwald, J. (1974) Defensive use by an insect of a plant resin. Science, 184, 996-999.

Evans, J.D., Aronstein, K., Chen, Y.P., Hetru, C., Imler, J.L., Jiang, H. et al. (2006) Immune pathways and defence mechanisms in honey bees Apis mellifera. Insect Molecular Biology, 15, 645-656.

Gillespie, J.P., Kanost, M.R. \& Trenczek, T. (1997) Biological mediators of insect immunity. Annual Review of Entomology, 42, 611-643.

Giorgi, M.S., Arlettaz, R., Christe, P. \& Vogel, P. (2001) The energetic grooming costs imposed by a parasitic mite (Spinturnix myoti) upon its bat host (Myotis myotis). Proceedings of the Royal Society of London Series B, Biological Sciences, 268, 2071-2075.

Hart, B.L. (1990) Behavioral adaptations to pathogens and parasites - five strategies. Neuroscience and Biobehavioral Reviews, 14, 273-294.

Hart, B.L. (2005) The evolution of herbal medicine: behavioural perspectives. Animal Behaviour, 70, 975-989.

Hawlena, H., Bashary, D., Abramsky, Z. \& Krasnov, B.R. (2007) Benefits, costs and constraints of anti-parasitic grooming in adult and juvenile rodents. Ethology, 113, 394-402.

Heil, M. \& McKey, D. (2003) Protective ant-plant interactions as model systems in ecological and evolutionary research. Annual Review of Ecology, Evolution and Systematics, 34, 425-453.

Holzer, B., Chapuisat, M., Kremer, N., Finet, C. \& Keller, L. (2006) Unicoloniality, recognition and genetic differentiation in a native Formica ant. Journal of Evolutionary Biology, 19, 2031-2039.

Lochmiller, R.L. \& Deerenberg, C. (2000) Trade-offs in evolutionary immunology: just what is the cost of immunity? Oikos, 88, 87-98.
Lozano, G.A. (1998) Parasitic stress and self-medication in wild animals. Advances in the Study of Behavior, 27, 291-317.

Martin, D., Tholl, D., Gershenzon, J. \& Bohlmann, J. (2002) Methyl jasmonate induces traumatic resin ducts, terpenoid resin biosynthesis, and terpenoid accumulation in developing xylem of Norway spruce stems. Plant Physiology, 129, 1003-1018.

Mooring, M.S., Blumstein, D.T. \& Stoner, C.J. (2004) The evolution of parasite-defence grooming in ungulates. Biological Journal of the Linnean Society, 81, 17-37.

Moret, Y. \& Schmid-Hempel, P. (2000) Survival for immunity: the price of immune system activation for bumblebee workers. Science, $\mathbf{2 9 0}$, $1166-1168$.

Moret, Y. \& Schmid-Hempel, P. (2004) Social life-history response to individual immune challenge of workers of Bombus terrestris L.: a possible new cooperative phenomenon. Ecology Letters, 7, 146-152.

Moret, Y. \& Siva-Jothy, M.T. (2003) Adaptive innate immunity? Responsive-mode prophylaxis in the mealworm beetle, Tenebrio molitor. Proceedings of the Royal Society of London Series B, Biological Sciences, 270, 2475-2480.

Narberhaus, I., Zintgraf, V. \& Dobler, S. (2005) Pyrrolizidine alkaloids on three trophic levels - evidence for toxic and deterrent effects on phytophages and predators. Chemoecology, 15, 121-125.

Phillips, M.A. \& Croteau, R.B. (1999) Resin-based defenses in conifers. Trends in Plant Science, 4, 184-190.

Rolff, J. \& Siva-Jothy, M.T. (2003) Invertebrate ecological immunology. Science, 301, 472-475.

Schmid-Hempel, P. (2003) Variation in immune defence as a question of evolutionary ecology. Proceedings of the Royal Society of London Series B, Biological Sciences, 270, 357-366.

Schmid-Hempel, P. (2005) Evolutionary ecology of insect immune defenses. Annual Review of Entomology, 50, 529-551.

Schwander, T., Rosset, H. \& Chapuisat, M. (2005) Division of labour and worker size polymorphism in ant colonies: the impact of social and genetic factors. Behavioral Ecology and Sociobiology, 59, 215-221.

Sheldon, B.C. \& Verhulst, S. (1996) Ecological immunology: costly parasite defences and trade-offs in evolutionary ecology. Trends in Ecology \& Evolution, 11, 317-321.

Siva-Jothy, M.T., Moret, Y. \& Rolff, J. (2005). Insect immunity: an evolutionary ecology perspective. Advances in Insect Physiology, 32, $1-48$.

Soderhall, K. \& Cerenius, L. (1998) Role of the prophenoloxidaseactivating system in invertebrate immunity. Current Opinion in Immunology, 10, 23-28.

Whitlock, M.C. (2005) Combining probability from independent tests: the weighted Z-method is superior to Fisher's approach. Journal of Evolutionary Biology, 18, 1368-1373.

Williams, G.C. (1966) Natural selection costs of reproduction and a refinement of Lack's principle. American Naturalist, 100, 687-690.

Accepted 10 December 2007

First published online 22 February 2008 